\title{
A INDÚSTRIA DE PETRÓLEO NO BRASIL: AVALIAÇÃO HISTÓRICA DA CONCEPÇÃO DA EMPRESA PETROBRÁS
}

\section{THE OIL INDUSTRY IN BRAZIL: EVALUATION OF HISTORIC DESIGN COMPANY PETROBRÁS}

\author{
Data do recebimento do artigo: 18/04/2012 \\ Data do aceite do artigo: 17/09/2012 \\ Data da publicação: 29/11/2012
}

\author{
Dra.Paula Meyer Soares ${ }^{1}$ \\ Doutorado em Economia de Empresas \\ Fundação Getúlio Vargas \\ Dr.Mauro Donizetti Berni \\ Doutorado em Planejamento de Sistemas Energéticos \\ Universidade Estadual de Campinas \\ Dr. Paulo C. Manduca \\ Doutorado em Sociologia \\ Universidade de São Paulo
}

RESUMO:

\begin{abstract}
A indústria petrolifera no Brasil remonta os anos 50. A crise mundial que eclodiu nos anos 30 impactou fortemente na trajetoria de crescimento da economia brasileira e de vários outros países. Inicia-se entao um lento e gradual processo de transição do modelo de crescimento economico assentado no setor externo para um modelo de substituição de importações cujo objetivo principal era fundar um parque industrial forte e competitivo capaz de gerar renda e empregos a solidez desse modelo dependia da consolidação de uma industria de base e pesada (infraestrutura) sólidas. Nesse sentido foi criada a empresa Petrobrás, durante o Governo Vargas e desde então o Brasil tornouse pioneiro na exploração e produção de petróleo no mercado mundial. O referido estudo fará uma retrsopectiva historica da industria petrolifera no Brasil considerando as suas particularidades e evolução do marco regulatório. A ideia central é analisar o contexto em que foi criada a Petrobrás e principais resultados alcancados nesse segmento nos dias de hoje. A metodologia utilizada baseou-se em referencial teórico que aborda o assunto e dados estatisticos que ilustrem essas mudanças regulatórias e economicas nesses anos desde a sua criação..
\end{abstract}

Palavras-Chave: petróleo, Petrobrás, economia, Lei № 9.478/1997.

\section{ABSTRACT:}

The brazilian oil industry dates back 50 years. The global crisis that erupted in the 30s impacted heavily on the trajectory of economic growth in Brazil and several other

\footnotetext{
${ }^{1}$ Autor para correspondência: Fundação Getúlio Vargas - Av. 9 de Julho, 2029, Bela Vista, São Paulo SP - Brasil CEP: 01313-902.
} 
countries. Then begins a slow and gradual process of transition from economic growth model seated on the external sector to a model of import substitution whose main objective was found a strong and competitive industrial park capable of generating income and jobs depended on the strength of this model consolidation of a heavy industry base (infrastructure) solid. Accordingly the company Petrobras was created during the Vargas government and since then Brazil has become a pioneer in the exploration and production of oil in the world market. This study will make a historic retrsopectiva oil industry in Brazil considering its peculiarities and evolution of the regulatory framework. The central idea is to analyze the context in which it was created Petrobras and main results achieved in this segment today. The methodology used was based on the theoretical framework that addresses the issue and statistical data illustrating these regulatory and economic changes over the years since its inception ..

KEYWORDS: oil, Petrobras, economics, Law 9.478/1997..

\section{INTRODUÇÃO}

A descoberta do petróleo no Brasil remonta os anos 30. Esse período coincide com o esgotamento do modelo de crescimento economico pautado no setor agroexportador.

A eclosão da crise na Europa e Estados Unidos provocaram uma queda abrupta nas exportações brasileiras. O governo brasileiro visando reverter tal quadro adotou na época medidas que amenizassem os efeitos perversos do recrudescimento da economia externa.

A adoção de regime cambial múltiplo, recompra de excedentes de produção, adoção de tarifas de importação diferenciadas para diversos setores da economia não foram suficientes para reverter a trajetória de crescimento incipiente.(PIRES et al, 2007)

Na época visando diminuir a dependencia externa, inicia-se um processo de substituição de importações pautado no desenvolvimento interno de setores intensivos em capital. O redirecionamento dos esforços e incentivos a setores manufatureiros visava desenvolver internamente a produção de bens obtidos no mercado externo até entao.

O desenvolvimento da indústria nacional foi um projeto almejado desde os anos 30 e perseguido pelos governos subsequentes.

A era Vargas foi marcada por projetos nacionais desenvolvimentistas vinculados a industrialização. A independencia economica do país e seu fortalecimento dependiam de politicas de fomento a industrialização, emprego e geração de renda.

Nesse sentido, Vargas adota um dos mais ousados projetos nacionais de construção nacional em que busca o fortalecimento da industria nacional e de setores de infraestrutura e modernização da agricultura.

O reposicionamento do Estado é fundamental enquanto agente articulador de tal empreitada. 
Naquela época, Vargas adotou uma série de programas de fomento a industria nacional e de empresas estatis em setores considerados estrategicos para 0 desenvolvimento economico do país - energia, petróleo, transporte e infraestrutura.

A Petrobrás nasceu durante esse periodo turbulento da história brasileira e transformou-se em simbolo de soberania e de progresso nacional.

Atualmente o país ocupa ocupa a $13^{\mathrm{a}}$ posição de reservas provadas mundiais de petróleo e gás. Em 2011, essas reservas equivaliam a 30.081,8 milhões barris/dia respectivamente. (Anuário Estatistico de Petróleo, Gás e Biocombustíveis, 2012)

Recentemente, deu-se início a produção de petróleo e gás na região do pré-sal. As previsões de produção são bastante otimistas e poderão alcançar a cifra de 167,5 mil barris/dia de petróleo e 5,3 milhões de m³/dia de gás natural, totalizando 200,6 mil barris de óleo equivalente/dia. Isso correspondeu a 7,5\% da produção nacional no final de 2011. Portanto a viabilidade técnica e comercial da extração de petróleo e gás natural abaixo da camada de sal existe e esse fator deve ser levado em conta.(ANP,2011)

O referido estudo fará uma abordagem histórica da indústria nacional de petróleo com enfoque na criação da Petrobrás. Serão analisados alguns aspectos do marco regulatório que a criou e principais modificações deste e seus efeitos na produção nacional de petróleo, gás e derivados.

O artigo foi estruturado em cinco partes, sendo a primeira esta introdução, nasequência a revisão bibliográfica, método de pesquisa e análise e discussão dos resultados e por fim, as considerações finais.

\section{REFERENCIAL TEÓRICO}

\subsection{ANTECEDENTES HISTÓRICOS}

No inicio do século XIX, a maior parte da população brasileira residia no campo. A indústria nesse período era quase imperceptível. A produção industrial voltava-se ao atendimento da demanda interna e de algumas atividades ligadas a principal produção do país- o cultivo e exportação de café. A produção têxtil,por exemplo,desenvolveu-se graças à necessidade de produção de sacaria e outros artefatos necessários a indústria do café.

Com a eclosão da crise que assolou as economias norte-americana e europeia impactou na dinâmica e na capacidade de crescimento de várias economias dentre elas a brasileira. As expectativas futuras de crescimento da economia mundial eram sombrias. Diante desse cenário, a manutenção de indicadores econômicos robustos era também uma incógnita.

$\mathrm{Na}$ época, o dinamismo da economia assentava-se no eixo externo, com a produção e exportação de matérias-primas para o mercado mundial. O arrefecimento da atividade econômica mundial refletiu fortemente no desempenho interno da economia brasileira.

Apesar dos esforços empreendidos diante da crise, era necessário buscar alternativas que visassem a manutenção dos indicadores econômicos obtidos até então. 
Nesse sentido, a produção passou a voltar-se para o mercado interno, ou seja, a atividade que determinava os níveis de emprego e de renda além do crescimento econômico. (PIRES et al, 2007)

A mudança do foco da politica econômica levou a adoção de políticas de concessão de credito a indústria e a restrição da oferta de café. Com a redução das importações devido a crise externa, alguns produtos passaram a ser produzidos internamente.

O processo de internalização da produção, ficouconhecido como sendo, processo de substituição de importações.

O motor de substituição de importações foi gerado pelo estrangulamento externo, o qual exigia uma reprodução e relativo porque tinha como limite a importação dos insumos industriais. Por outro lado, a importação funcionava como estimulo e limite ao investimento industrial. A industrialização do pais influiu na urbanização e no surgimento de outras classes sociais que mais tarde desempenhariam papel central na condução econômica e politica do país.

\subsection{A ASCENSÃO DE VARGAS AO PODER E A INDUSTRIALIZAÇÃO TARDIA}

A crise de 30 interrompeu a trajetória ascendente de crescimento da economia brasileira. O ambiente externo era marcado pela incerteza e insegurança dos rumos que a economia brasileira deveria tomar. Em 1930, a atividade econômica contraiu 2,1\% e no ano seguinte não foi diferente disso, a retração foi ainda pior 3,3\%. (PIRES et al, 2007) Internamente, a fragilidade e incerteza politica contribuíam para o enfraquecimento da oligarquia cafeeira e a ascensão de outros segmentos políticos cujo anseio era de reconstruir um pais forte e independente guiado pela mão do Estado.

Foi nesse contexto de incerteza e fragilidade economia e politica que Vargas assume o poder em 1930.(PIRES et al, 2007)

A transição para um novo modelo de crescimento econômico ocorre de forma gradual. O processo de industrialização brasileiro nos anos 30 a 50 ocorreu por meio de parcerias com capital estrangeiro.

$\mathrm{Na}$ época, Vargas entendia que a consolidação de um projeto nacional dependeria de uma posição politica forte e de recursos que possibilitassem a construção de um parque industrial que atendesse a demanda interna da população com a produção de produtos voltados a esta.

O programa de desenvolvimento priorizava os setores do Departamento I onde estavam incluídos uma série de empreendimentos estratégicos - Companhia Siderúrgica Nacional, Petrobras, Companhia do Vale do Rio Doce, Eletrobrás, etc.

Vale ressaltar que esse programa de crescimento baseado nos setores de infraestrutura não excluía por completo a participação do capital estrangeiro. Vargas entendia que o processo de maturação da indústria nacional não poderia coexistir sem esse capital (PIRES et al (2007). 


\subsection{PETROBRAS: SÍMBOLO DE UMA NOVA ERA.}

A criação da Petrobras ocorre em 1953. O período que antecedeu a sua criação foi bastante tenso politicamente. Na verdade, em 1948, durante o Governo de Dutra, foi enviado ao Congresso Nacional para a apreciação o Estatuto do Petróleo. Se aprovado o Estatuto permitia a participação da iniciativa privada na indústria de combustíveis. Uma vez que não haviam empresas nacionais com recursos financeiros e tecnologia adequados para a exploração da atividade petrolífera.

A bancada oposicionista do Congresso foi efusiva diante da ideia de "entregar" a iniciativa estrangeira o direito de exploração dos recursos minerais do país. O monopólio foi proposto pelos nacionalistas da UDN que considerava a questão do petróleo como sendo assunto de Estado. A entrada de outras empresas estrangeiras na exploração do petróleo e derivativos poderia ser uma ameaça a soberania nacional. (PIRES, et al (2007).

Naquele período a produção mundial concentrava-se nas mãos de algumas empresas norte-americanas, conhecidas como "Sete Irmãs" e a decisão nacional de estender o direito de exploração e produção de petróleo foi simplesmente refutada e isso fez com surgisse o famoso movimento“ O Petróleo é Nosso”.

A mobilização popular impediu a entrada de empresas estrangeiras nesse segmento e dai surge o monopólio estatal, a Petrobras, com a aprovação da Lei 2.004/53.

A Petrobras foi concebida em um momento histórico em que o país gestava um projeto nacional de desenvolvimento. A proposta nasceu durante o Governo Vargas.

Com a eclosão do Segundo Choque do Petróleo em 1979, o país entra em um período critico de equilíbrio interno e externo. Os indicadores inflacionários tomam as manchetes dos jornais e a divida publica explode.

Inicia-se um movimento na direção da internacionalização das atividades da Petrobras e na possível associação desta empresa outras empresas privadas. Nos anos 80, foi enviado ao Congresso Nacional duas emendas que tratassem do assunto supracitado. A associação com outras empresas privadas na prestação de serviços e fabricação de equipamento foi rejeitada mas a internacionalização foi aprovada.

A Petrobras é atualmente a maior empresa da América Latina, a quarta maior empresa petrolífera de capital aberto e de energia do mundo. Desenvolve atividades de exploração, produção e de refino em 28 nações diferentes. O Plano de Negócios 2010 a 2014 prevê investimentos de US\$224 bilhões. Desenvolve também atividades de compra e venda de petróleo, tecnologias, equipamentos, materiais e serviços; acompanhamento do desenvolvimento das economias americana e européia; operação financeira com bancos e bolsa de valores; recrutamento de pessoal especializado; afretamento de navios; apoio em eventos internacionais, entre outros.

A Petrobras é uma sociedade anônima de capital aberto, cujo acionista majoritário é o Governo do Brasil. Além dessa atividades, possui expertise na exploração de poços em águas profundas e ultraprofundas, passando a ser vista como um benchmarking nesta área. Portanto, a empresa pode passar a ser uma exportadora de tecnologia, elevando o nível do Brasil como um todo no cenário mundial atual.(AZEVEDO et al, 2011) 
Com a abertura da economia ocorrida no inicio da década de 90 e a necessidade de atração de capital estrangeiro e novos investimentos na área de petróleo e gás, a promulgação da Lei 9.478\1997, conhecida como a "Lei do Petróleo", possibilitou a entrada de empresas nacionais e estrangeiras na exploração de petróleo e gás. Os resultados desse novo marco regulatório e suas repercussões serão conhecidos e discutidos nesse estudo.

\section{METODOLOGIA}

A realização do referido estudo adotou o seguinte procedimento metodológico a pesquisa bibliográfica. Segundo GIL (1999), a pesquisa bibliográfica consiste no uso de referencial teórico (livros, artigos acadêmicos, textos para discussão, anuários) que aborda e contextualiza a temática estudada. Por meio dessas bibliografia reúne-se conhecimentos sobre o assunto e suas relações guardadas entre si.

Quanto ao seu objetivo, a pesquisa é explicativa. Na visão de ANDRADE (2002), “ a pesquisa explicativa é um tipo de pesquisa mais complexa, pois, além de registrar, analisar, classificar e interpretar os fenômenos estudados, procura identificar seus fatores determinantes.

A realização do estudo baseou-se em dados estatísticos de produção, reservas provadas e extensão das bacias sedimentares com o intuito de ilustrar o potencial petrolífero e da indústria de gás após a promulgação da Lei do Petróleo.

A seguir faremos as discussões dos resultados obtidos com a promulgação da lei.

\section{ANALISE E DISCUSSÃO DOS DADOS}

\subsection{A LEI DO PETRÓLEO EM SUA ESSENCIA}

Em 1997, foi promulgada a Lei 9.478/1997 que dispõe sobre a política energética nacional, as atividades relativas ao monopólio do petróleo bem como a instituição do Conselho Nacional de Política Energética (CNPE) e a Agência Nacional do Petróleo (ANP).

Em linhas gerais, a política nacional energética deverá:

- preservar o interesse nacional e proteger o meio ambiente;

- promover o desenvolvimento, de tal modo a ampliar o mercado de trabalho e a valorização dos recursos energéticos;

- evitar os abusos dos interesses do consumidor via preço, qualidade e oferta dos produtos;

- promover e incrementar, em bases econômicas, a utilização do gás natural, utilizando fontes alternativas de energia; (Art $1^{\circ}$ )

Dito de outra forma, a política energética nacional reveste-se do uso racional dos recursos naturais potenciais e que possam servir de fonte de energia - renováveis ou não. O uso adequado e eficiente de tais recursos requer a instituição de órgãos que fiscalizem e regulamentem a produção e exploração de petróleo. 
Assim como a garantia do fornecimento de energia por meio da adoção de medidas que fomentem o desenvolvimento e a geração de empregos nas regiões do país se fazem presentes no ordenamento jurídico. A fiscalização e regulamentação dessas atividades ficarão sob a responsabilidade do Conselho Nacional de Energia (CNE) e a Agencia Nacional de Petróleo (ANP). .

A criação do Conselho Nacional de Energia, o CNE, ocorre no momento em que há a necessidade em promover o aproveitamento racional dos recursos energéticos do País, respeitando as particularidades e características regionais do país.(GIAMBIAGI e LUCAS, 2013)

A instituição do CNE também possibilitará a revisão periódica das matrizes energéticas aplicadas às diversas regiões do País, considerando as fontes convencionais e alternativas e as tecnologias disponíveis.

Antes da "Lei do Petróleo", o monopólio da União sobre essas atividades e as de refino, transporte, importação e exportação de petróleo, seus derivados e gás natural, era exercido exclusivamente pela empresa estatal Petrobrás.

Em 1995, o monopólio da Petrobras foi extinto por meio da Emenda Constitucional no 9/1995. Caberá a União contratar empresas estatais e privadas para a realização das atividades de exploração e produção de petróleo e gás natural, objeto do monopólio estatal.(PINTO JR et al, 2007)

No que tange a regulamentação e fiscalização das atividades econômicas das indústrias do petróleo e do gás natural, tal função caberá a Agencia Nacional de Petróleo, Gás, Biocombustíveis e Derivados, a ANP. Essa regulação será realizada por meio do consentimento do ingresso de empresas no mercado, mediante autorizações, permissões e concessões. Além de celebrar em nome da União, os contratos delas decorrentes; e fiscalizar a sua execução.

Essas autorizações concedidas a empresas que tenham o interesse em desenvolver atividades no ramos petrolífero e de gás. A concessão e a exploração das reservas de petróleo ocorrerão em duas fases distintas: a exploração e a produção. A concessão implicará na exploração por livre conta e risco produzir petróleo ou gás natural em determinado bloco. A lei confere propriedade desses bens após a extração, com encargos relativos ao pagamento dos tributos incidentes e das participações legais ou contratuais correspondentes.

Em 2011, segundo dados da ANP, existiam no país 736 áreas estavam sob concessão: 324 blocos na fase de exploração, 80 campos em desenvolvimento da produção e 332 campos na etapa de produção. (ANP, 2011)

O Brasil possui ao todo 29 bacias sedimentares e para cada bacia há um determinado número de blocos a serem explorados onde são desenvolvidas atividades de exploração ou produção de petróleo e gás natural.(ANP,2011)

A delimitação dos blocos oferecidos em cada uma das Rodadas da ANP está condicionada à disponibilidade de estudos geológicos que demonstrem indícios da presença de petróleo e gás natural bem como considerações sobre os efeitos ao meio ambiente e outros aspectos técnicos. A seleção final será realizada de acordo com as diretrizes do CNPE, e em conformidade a Resolução CNPE $n^{0}$ 8/2003 e Lei $n^{\circ}$ $12.351 / 2010$. 
Após a quebra do monopólio do petróleo, empresas nacionais e estrangeiras devidamente habilitadas poderão participar das licitações para exploração, desenvolvimento e produção de petróleo e gás. Entretanto, para se tornarem concessionárias ou contratadas devem ser constituídas sob as leis brasileiras, com sede e administração no País. Os processos licitatórios transcorrem sob regras claras e ampla transparência.

\subsection{POTENCIAL PETROLIFEROS E GASÍFERO DO BRASIL}

A promulgação da Lei do Petróleo permitiu a expansão da capacidade produtiva e exploratória da indústria nacional de petróleo e gás.

Em 2011, o Brasil respondeu por 2,6\% da produção de petroleo mundial. A Arabia Saudita por sua vez teve uma participação de 13.35\%. Apesar da participação brasileira não ser tão expressiva quando comparada com outros países produtores mundiais, a qualidade do petroleo brasileiro é de boa qualidade, leve. Essa característica coloca o país em um mercado cativo de petroleo mundial em que a pureza e qualidade do petroleo possibilitam a produção de outros produtos derivados como por exemplo: óleo diesel, gasolina, querosene, gás natural, gás liquefeito de petróleo (GLP).

Em 2010 o consumo mundial de petróleo era da ordem de 87.439 mil barris/dia contra 88.034 mil barris/dia no ano subsequente. Esse aumento de 0.68\% aparentemente inexpressivo em um período de 5 anos significa que o planeta deve ser capaz de oferecer pelo menos 5.5\% . (Anuário Estatistico de Petróleo, Gás e Biocombustíveis, 2012)

Apesar da expansão gradual do consumo de petróleo observamos também a descoberta de novas reservas provadas de petróleo ao redor do mundo. O Brasil detém 15,1 milhões de m3 de reservas de petróleo provadas enquanto que o mundo detém 1.652,6 milhões de m3 destas reservas.(Anuário Estatistico de Petróleo, Gás e Biocombustíveis, 2012)

No que tange a distribuição das reservas provadas de petróleo - mar e terra podemos observar no quadro 3 que a maior parte do potencial brasileiro encontra-se em mar. A Amazônia detém 11\% do potencial das reservas provadas de petróleo em terra. A maior parte do petróleo brasileiro encontra-se no mar. Os estados do Rio de Janeiro, Rio Grande do Norte, Espírito Santo e São Paulo concentram as principais reservas provadas de petróleo do país. (Anuário Estatistico de Petróleo, Gás e Biocombustíveis, 2012)

O potencial maior do país encontra-se em alto mar em águas profundas e isso requer habilidade e tecnologias apropriadas para a extração do petróleo. O estão do Rio de Janeiro detém 85\% das reservas provadas de petróleo do país. Essa concentração de reservas em um único estado levou a revisão da lei de royalties do petróleo em 2012.2

\section{CONSIDERAÇÕES FINAIS}

\footnotetext{
${ }^{2}$ Em maio/2013 foi criada comissão para relatar e discutir o PL 5.500/13 que discute sobre adestinação dos royalties do petróleo. A idéia é que todos os royalties sejam direcionados para a educação. Os resultados dessa discussão ainda estão em andamento no $\mathrm{CN}$.
} 
A exploração de petróleo e gás no Brasil não é recente. A evolução da indústria nacional de petróleo data da era Vargas.

A eclosão da crise em 1929 e o arrefecimento da atividade econômica mundial levaram o país a repensar e a adotar um novo modelo de crescimento econômico impulsionado pelas forças de mercado existentes na economia brasileira. Ou seja, o motor propulsor da economia deveria ter como centro a dinâmica do mercado interno. Considerando tal fato, iniciou-se um amplo processo de industrialização promovido a partir da substituição de importações.

Nos anos 50, tínhamos um parque industrial desenvolvido para a época graças as medidas e incentivos adotados em prol da industrialização. Nesse período Vargas estava no comando do país e a industrialização era o caminho para que o país pudesse exercer definitivamente a sua soberania. Sendo assim foi enviada ao Congresso Nacional a proposta de criação de uma empresa nacional de exploração e produção de petróleo.

$\mathrm{Na}$ época Vargas vislumbrava a criação de uma empresa que explorasse o potencial existente no país. Em nenhum momento Vargas se opôs quanto a participação de outras empresas - sejam de capital nacional ou estrangeiro - na exploração de tal atividade. No entanto, a oposição no Congresso Nacional, não permitiu e entendeu que as riquezas naturais e minerais da nação deveriam pertencer e estar aos cuidados da Uniao. Sendo assim foi criada a Petrobras em 1953, por meio da Decreto-lei 2.004.

A criação da Petrobrás foi um marco para a indústria nacional do país. A produção nacional hoje ocorre com a participação de empresas nacionais e estrangeiras.

Em 1997, foi promulgada a Lei 9.478, conhecida como Lei do Petróleo. A instituição de um ordenamento específico para o setor reflete o amadurecimento do país com respeito às questões econômicas, sociais e ambientais que envolvem a exploração das atividades de petróleo e gás. Esse marco regulatório fornece as diretrizes gerais sobre a política energética nacional e as funções exercidas pelos dois principais órgãos fiscalizadores e reguladores do setor -Agencia Nacional de Petróleo (ANP) e o Conselho Nacional de Energia (CNE).

É sabido que o Brasil é um país de dimensões intercontinentais. O país detém uma das maiores bacias de gás natural existentes no mundo. Recentemente a descoberta de novos poços de petróleo na camada do pré-sal são fatos que exigem a adoção de procedimentos legais e técnicos que protejam os direitos dos cidadãos que habitam nessas regiões de descobertas..

Ao longo desses anos o país diversificou a sua matriz energética aproveitando o potencial energético existente nessa região. A geração de energia a partir do potencial hídrico das bacias fluviais amazonenses deu inicio a exploração de outras fontes de energia - solar, biomassa, petróleo e gás natural.

A descoberta do ouro negro na camada de pré-sal será mais um desafio a ser enfrentado pela indústria nacional de petróleo. Por outro lado, o país caminha na direção em ocupar lugar de honra com os principais produtores de petróleo mundiais e isso significará no longo prazo autossuficiência e independência econômica. Portanto, compreender a evolução dessa importante indústria ate o presente momento é primordial para que possamos estabelecer as outras diretrizes e caminhos a serem trilhados pelo setor. 


\section{REFERÊNCIAS}

ABADIE,E. Apostila sobre processos de refinação, PETROBRÁS/RH/UC/DTA.2003. ANUARIO ESTATISTICO DE PETRÓLEO E GÁS. Disponível em www.anp.gov.br. ANDRADE, Maria Margarida de. Como preparar trabalhos para cursos de pósgraduação: noções práticas, Ed Atlas, São Paulo, 2002.

ALMEIDA, E. Fundamentos de Economia da Energia - Petróleo. Rio de Janeiro, COPPEAD/UFRJ, 2003.

BASTOS , V.D. Desafios da petroquímica brasileira no cenário global. BNDES Setorial, Rio de Janeiro, n.29, p.321-358, mar.2009.

GIAMBIAGI, Fabio e LUCAS, Luiz P V. Petróleo - reforma e contrarreforma do setor petrolífero, Ed Campus, Rio de Janeiro, 2013.

GIL, AntonioC.Métodos e Técnicas de Pesquisa Social, São Paulo, Atlas, 1999

PIRES et al. Economia Brasileira - da Colônia ao Governo Lula, Ed Saraiva, São Paulo, 2007.

PINTO JR, Helder Q Economia da Energia, Ed Campus, Rio de Janeiro, 2007. 